\title{
Honduras: Joint Staff Advisory Note on the Poverty Reduction Strategy Paper Second Annual Progress Report
}

The attached Joint Staff Advisory Note (JSAN) of the Poverty Reduction Strategy Paper Progress Report for Honduras, prepared jointly by the staffs of the World Bank and IMF, was distributed with the member country's Poverty Reduction Strategy Paper (PRSP) to the Executive Boards of the two institutions. The objective of the JSAN is to provide focused, frank, and constructive feedback to the country on progress in implementing its Poverty Reduction Strategy (PRS).

To assist the IMF in evaluating the publication policy, reader comments are invited and may be sent by e-mail to publicationpolicy@imf.org.

Copies of this report are available to the public from

International Monetary Fund • Publication Services

$70019^{\text {th }}$ Street, N.W. • Washington, D.C. 20431

Telephone: (202) 623-7430 • Telefax: (202) 623-7201

E-mail: publications@imf.org • Internet: http://www.imf.org

Price: $\$ 15.00$ a copy

\section{International Monetary Fund Washington, D.C.}





\title{
INTERNATIONAL MONETARY FUND AND \\ INTERNATIONAL DEVELOPMENT ASSOCIATION
}

\section{HONDURAS}

\section{Joint Staff Advisory Note on the Poverty Reduction Strategy Paper Second Annual Progress Report}

\author{
Prepared by the staffs of the International Monetary Fund \\ and the International Development Association \\ Approved by Markus Rodlauer and Donal Donovan (IMF) \\ and Pamela Cox (IDA)
}

March 7, 2005

\section{OVERVIEW}

1. The second annual Poverty Reduction Strategy Paper (PRSP) Progress Report (APR) of the Government of Honduras (GOH) presents a comprehensive review of the government's implementation of the PRSP to date. The APR presents the results of the implementation of the PRSP ${ }^{1}$ presented to the Boards of the IMF and IDA in October 2001. It incorporates inputs from government, civil society, and the donor community. It addresses seven key areas: (i) the consultation process; (ii) review of the medium-term macroeconomic framework; (iii) progress in poverty reduction, targets and intermediate indicators;

(iv) evolution of poverty spending; (v) implementation of policies ${ }^{2}$ to date by programmatic area and medium-term programming; (vi) monitoring and evaluation; and, (vii) challenges to PRSP implementation. Donors expressed strong support to the PRSP process at the Consultative Group (CG) meeting in June 2004, where the GOH presented a progress report on PRSP implementation during 2003. The government and stakeholders also expressed their continued commitment to the process, and jointly with donors have intensified efforts to improve donor coordination to align external cooperation with national priorities.

\footnotetext{
${ }^{1}$ Estrategia de Reducción de la Pobreza, Government of Honduras, July 2001.

${ }^{2}$ The five strategic policy areas are: (i) prioritization of actions that aim to reduce poverty in a sustainable manner; (ii) prioritization of actions favoring the least developed groups and areas of the country; (iii) strengthening of civil society participation and decentralization in the PRS; (iv) strengthening of governance and participatory democracy within the PRS framework; and (v) reduction of environmental vulnerability and its impact on poverty.
} 


\section{Progress in Implementation of the Poverty Reduction Strategy}

\section{A. Consultation Process}

2. The government intensified efforts to broaden participation and increase local level involvement in PRSP implementation, and in consultations for the APR in coordination with the PRSP Consultative Council. Consultations for the APR took place through six regional workshops to ensure civil society participation, including donors' attendance, and the APR was distributed to donors for comments. ${ }^{3,4}$ Approximately eight hundred people participated in the consultation process, mostly civil society representatives and donors. The PRSP, the APR, and other relevant material to the PRSP are posted on both websites of the Ministry of Finance (Secretaria de Finanzas or SEFIN):

http://www.sefin.gob.hn/erp.html, and the SIERP website: $\underline{\text { http://www.sierp.hn. }}$

3. The APR has incorporated important contributions from the consultation process, such as strengthening the employment component, emphasizing participation and decentralization in PRSP implementation, increasing transparency in monitoring and evaluation, and improving alignment of PRSP interventions to PRSP goals. Civil society proposals have been compiled in a matrix contained in Appendix E of the APR. Discussions covered the six PRSP programmatic areas and specific issues were raised. In particular, many groups expressed the need to urgently improve the impact of the strategy on growth, employment and poverty reduction. Participants also emphasized the need to strengthen overall competitiveness and to reduce inefficiencies in the use of state funds and external resources.

\section{B. Medium-Term Macroeconomic Framework}

4. Although the APR presents the government's updated medium-term macroeconomic framework, a more in-depth discussion of how it will be achieved under the envisaged policies would be useful. The framework, which is consistent with the government's economic program being supported by the PRGF arrangement (table below) aims at achieving sustainable growth, reducing poverty, and maintaining macroeconomic and financial stability. The strategy involves continuing structural reforms and prudent macroeconomic policies. Reforms to boost growth focus on strengthening the development of human capital and basic infrastructure, improving the environment for private sector

\footnotetext{
${ }^{3}$ Donors in Honduras participated through the G-17 group, which was originally constituted to follow up on the Stockholm declaration and which now serves as a coordinating group for multilateral and bilateral donors.

${ }^{4}$ The consulted regions were: (i) Central, provinces of Francisco Morazán, Comayagua, La Paz and Olancho, (ii) South, provinces of Valle and Choluteca, (iii) Western, provinces of Copán, Ocotepeque, Lempira and Intibucá, (iv) North, provinces of Cortés and Santa Bárbara, (v) Seaboard, provinces of Atlántida, Islas de la Bahía and Yoro, and (vi) Bajo Aguan, provinces of Colón and Gracias a Dios.
} 
development, and using international trade agreements (including CAFTA). These reforms are expected to lay the basis for sustainable higher growth rates in the coming years.

5. The fiscal strategy embedded in the PRGF is based on the gradual reduction of the fiscal deficit, while at the same time orienting spending toward priorities (growthenhancing investment and poverty spending). Key reforms supporting this strategy include broadening the tax base, strengthening tax administration, upgrading the Integrated Public Financial Administration System (SIAFI), introducing the single treasury account, and the gradual restructuring of the public sector. However, the risks to the fiscal strategy are significant, as described in section III.A below.

\begin{tabular}{|c|c|c|c|c|c|c|c|}
\hline \multicolumn{8}{|c|}{ Honduras: Macroeconomic Framework } \\
\hline & \multirow{2}{*}{$\begin{array}{l}\text { Prel. } \\
2003\end{array}$} & \multirow{2}{*}{$\begin{array}{c}\text { Prel. } \\
2004\end{array}$} & \multicolumn{5}{|c|}{ Projection } \\
\hline & & & 2005 & 2006 & 2007 & 2008 & 2009 \\
\hline \multicolumn{8}{|c|}{ (Percent of GDP, unless otherwise stated) } \\
\hline Real GDP (growth, in percent) & 3.5 & 4.6 & 4.2 & 4.5 & 4.5 & 4.5 & 4.5 \\
\hline Inflation (eop, in percent) & 6.8 & 9.2 & 6.9 & 5.0 & 4.0 & 3.0 & 2.5 \\
\hline Total revenues and grants & 27.4 & 28.7 & 29.4 & 29.0 & 28.9 & 28.7 & 28.7 \\
\hline Capital expenditures & 6.2 & 6.5 & 7.7 & 7.2 & 7.6 & 7.7 & 8.1 \\
\hline Overall combined public sector balance & -5.1 & -3.0 & -2.5 & -1.7 & -1.7 & -1.6 & -1.6 \\
\hline Primary combined public sector balance & -4.6 & -2.6 & -2.3 & -1.7 & -1.7 & -1.7 & -1.7 \\
\hline Public sector debt $1 /$ & 75.3 & 72.8 & 56.1 & 54.0 & 51.7 & 49.6 & 47.7 \\
\hline External current account balance & -4.2 & -5.2 & -2.5 & -2.4 & -2.7 & -3.2 & -3.7 \\
\hline Gross international reserves & & & & & & & \\
\hline in months of imports & 3.7 & 4.8 & 4.9 & 4.9 & 4.9 & 4.8 & 4.6 \\
\hline Public external debt $1 /$ & 69.8 & 67.8 & 51.6 & 49.7 & 47.9 & 46.1 & 44.5 \\
\hline
\end{tabular}

\section{In 2005, the authorities' fiscal strategy will rely on reaping the full benefits of} the 2002-03 tax reforms, further improvements in tax administration, strict control over expenditures (including the wage bill), and contingent spending cuts. The authorities are committed to decisively implementing the revised tax code approved in December 2004, including their power to determine taxpayer's income through indirect methods. Their action plan aims at further improving tax administration by reducing taxpayer arrears, stopfilers, and strengthening tax audits. The 2005 budget established a prudent expenditure policy, including on public wages. As a result of these policies and higher grants, the deficit of the consolidated public sector (after grants) will fall by 0.5 percent of GDP, while public investment will rise by over 1.0 percent of GDP and poverty spending by 0.3 percent of GDP. The main offsetting savings are in the wage bill, domestically financed goods and services (i.e., net of programs funded by the Education-for-All and Global Health Fund initiatives), and current transfers. 
7. The APR could have provided a more in-depth analysis of the effects on poverty of growth, and of labor market and financial sector reforms. The APR contains a useful study of the geographic distribution of poverty, with emphasis on rural and urban areas, but the analysis of labor market conditions is limited. Also, a discussion of the effects of the recent financial system reforms on poverty reduction would have been welcome. The next PRSP progress report would benefit from a thorough discussion of these effects, particularly the availability of financial services to the poor. The next Report should also explain in detail the mechanism through which higher growth would lead to the targeted reduction in poverty, and if feasible, focus on the different demographic groups and geographical distribution of the poor.

\section{Poverty Reduction}

8. The APR adequately stresses the modest progress made in poverty reduction so far, and consistently with current government efforts, staffs concur that stepping up policies and programs to achieve the MDGs would be needed over the coming years. While the share of the total population living in poverty fell only from 66 percent in 1999 to 64 percent in 2004, the share living in extreme poverty declined from 49 percent to 44.6 percent. This lack of faster improvements in poverty reduction appears to be linked (with lags) to the low growth experienced during the initial years of this decade, together with the adverse impact of agricultural commodity prices. The reversal of both processes, as envisaged in the medium-term framework, augurs well for poverty reduction in future years. While the PRSP targets for extreme poverty were achieved in 2001 and 2002, they were not achieved in 2003 or 2004, even though economic growth has been recovering in the last two years. This suggests that the link between growth and poverty reduction may be operating with a lag. The APR clearly identifies this disappointing outcome and informs on progress achieved during 2003 and 2004 on efforts to prioritize programs and improve targeting, decentralize and improve service delivery, enhance public sector management, and realign donor assistance. All these efforts constitute good progress in the right direction and clearly reinforce the need to continue focusing on increasing the impact and cost-effectiveness of the resources devoted to anti-poverty programs ( 8 percent of GDP, or nearly 30 percent of total public spending).

9. Staffs attach particular importance to ongoing efforts towards updating welfare analysis in Honduras, and suggest incorporating its findings in the next PRSP progress report. With regard to statistical capacity, the National Institute of Statistics (Instituto Nacional de Estadística or INE) has continued to improve the systematic analysis of poverty and is enhancing poverty measurement through the first Living Standard Measurement Survey (LSMS), which just completed its field operations this past December 2004. The Technical Unit of the Presidency (Unidad de Apoyo Técnico or UNAT) and INE are 
collaborating with the Bank in the elaboration of a Poverty Assessment, ${ }^{5}$ including ways of enhancing the impact of growth on poverty reduction and of identifying key interventions to achieve PRSP/MDG goals.

\section{Targets and Intermediate Indicators}

10. There have been important improvements in attaining PRSP goals in 2004, even as execution capacity needs to be strengthened and the fiscal situation consolidated. Three out of every four PRSP monitorable goals were met in 2004, in contrast to the record in 2002 and 2003, when only about one-third to one-half of the goals were achieved. These outcomes have been influenced by increased and appropriate PRSP implementation efforts focused in allocating resources to prioritized actions. A relatively modest 2 percent annual growth rate in real per capita GDP was finally attained in 2004, after an extended period of zero or even negative rates. The elasticity of poverty reduction to economic growth has been characteristically low in Honduras, and consequently higher per capita GDP as well as other key contributing inputs are required to distribute the benefits from growth and for steady progress in most PRSP/MDG goals. Progress in education has improved, particularly for the third cycle of basic education, which is encouraging for human capital skills that need to be improved, particularly in the context of CAFTA. Coverage of electricity, telephone lines and sanitation services has also improved significantly. However, advancement in goals lagging behind call for prioritized efforts towards improving access to water and education coverage for the first and second cycle. Access to water, in particular, has been found to be critical for progress in both child mortality and malnutrition. The latter indicators have improved in the past (new data are not available to assess them in 2004), but concerns are raised that future progress could be hindered due to lack of progress in water coverage, insufficient coverage of effective nutrition and early childhood development programs, and gaps in the health system. Similarly, slow progress in basic education is worrisome, particularly among the extreme poor, as most PRSP/MDGs are strongly associated to female literacy.

\section{E. Policies and Programs}

\section{Budgetary programming needs to be better aligned to PRSP goals. Ongoing} efforts for establishing an MTEF and improving donor harmonization adequately aim towards improving progress in PRSP goals. They would need to be supported by developing cost-effectiveness criteria at the sectoral levels for program prioritization. A recently approved Organic Budgetary Law sets the legal basis for developing a Medium-term Expenditure Framework (MTEF), which should help to improve the linkages between budgetary programming and PRSP goals. Since the last assessment, the authorities have also established an enhanced operational mechanism to support PRSP goals through six sector-

\footnotetext{
${ }^{5}$ The Poverty Assessment will complement the recently published Honduras Development Policy Review on Accelerating Broad-Based Growth, World Bank Report No. 28222-HO, November 8, 2004.
} 
based coordinating boards (Mesas Sectoriales) seeking program alignment and donor harmonization.

\section{The GOH is contributing to the sustainability of the PRSP strategy by} improving governance. Staffs encourage the authorities to continue consolidating efforts towards more transparent management of public funds. Toward this end, the constitutional decree separating the National Electoral Council (Tribunal Nacional de Elecciones or TNE) and the National Individuals Registry (Registro Nacional de las Personas or RNP) has been ratified and public audit functions have been strengthened through the creation of a new Supreme Audit Court (Tribunal Superior de Cuentas or TSC). Such reorganization of responsibilities and enhanced auditing, together with improvements in public financial management and procurement, constitute substantial progress in the promotion of greater fiscal transparency.

\section{The authorities should ensure that the economic gains from DR-CAFTA trade} agreement and deeper regional integration efforts are maximized and shared across the population. These gains, which would stem from expanded and more permanent market access to the United States (Honduras' major trading partner) and from associated structural reforms, are expected to lead to higher investment, exports, and growth. While long tariff phase-out periods of 10,15 and 20 years were negotiated for the most sensitive commodities, the authorities should determine the possible need for compensatory measures to mitigate potential social impacts on specific sectors (e.g., traditional agriculture). The APR informs that the authorities are expected to commission a PSIA study on CAFTA by June 2005, in line with IDA and Fund staffs' suggestion. Staffs suggest incorporating these results into the next PRSP progress report.

\section{F. Public Expenditure Management}

\section{The mechanism for tracking the budgetary savings from HIPC debt relief is} adequate, and its operation is satisfactory to the Fund and IDA. The new poverty reduction framework (FRP) adequately keeps track of the fiscal savings resulting from HIPC relief and systematically monitors the channeling of those savings toward poverty reducing activities. The previous $\mathrm{FRP}^{6}$ has been reformed to render it more compatible with the expanded definition of poverty-reducing spending. ${ }^{7}$ The authorities have replaced the poverty fund, created in 2002 (Decree 70-2002) by a virtual fund, similar to those used in

\footnotetext{
${ }^{6}$ Fondo para la Reducción de la Pobreza (FRP).

${ }^{7}$ The expanded definition of poverty-reducing spending, which was supported by the staffs because it permits establishing a more accurate link between poverty-reducing spending and poverty outcomes, is described in the Honduras PRSP First Progress Report (available at: http://www.sierp.hn/docs/primer_anio_erp.pdf).
} 
other HIPC countries. ${ }^{8}$ Virtual funds track poverty spending through the 'tagging' of specific expenditures in the budget. The corresponding legislative reform has been approved, and operating guidelines for this fund and its consultative council have been drafted; all are readily accessible on SEFIN's website ${ }^{9}$ and SIERP's website. ${ }^{10}$ The tagging of povertyreducing spending was already incorporated into the 2004 budget and in the 2005 budget and both budget planning and execution of PRSP-related spending are managed by SEFIN through SIAFI. Under the current tracking system, the Central Bank of Honduras calculates the total budgetary savings from HIPC debt relief for each year. This information is incorporated into the national budget, which identifies all public spending and transfers associated with the poverty-reducing programs identified in the PRSP, as well as all other external and internal sources of financing for those programs. With this information, which is publicly available, it has been possible to verify that the increase in external resources inflows, including from HIPC debt relief, have been dedicated to poverty-reducing activities, with no substantial decline in domestic resources previously allocated to these activities. ${ }^{11}$ The authorities have met satisfactorily the targets for poverty spending as a share of GDP. ${ }^{12}$

\section{While significant improvements have taken place in public sector expenditure} management, further efforts are needed. The costing and financing of the PRSP strategy is broadly appropriate and in line with the macroeconomic framework supported by the PRGF arrangement. However, areas needing continued efforts are: (i) developing the government's capacity to manage, monitor, evaluate and improve PRSP implementation by giving all stakeholders access to mechanisms that effectively integrate their participation in the design and monitor of the government's poverty reduction programs; (ii) supporting the implementation of the Public Human Resource Reform thereby ensuring a more equitable working environment with better performance incentives and improved civil service quality, and improving public service management and delivery in key economic and social sectors; and (iii) strengthening the government's fiscal, financial and fiduciary management, resulting in a more accurate, timely, relevant and transparent public sector. These are areas that the Bank is currently supporting through IDA's Poverty Reduction Strategy Technical Assistance Credit (PRS TAC) cofinanced by the Government of Sweden and the Government of the United Kingdom.

\footnotetext{
${ }^{8}$ Virtual and poverty funds are contrasted in the Joint World Bank-IMF paper on "Tracking of Poverty-Reducing Spending in Heavily Indebted Poor Countries (HIPCs)," March 27, 2001 (www.imf.org or www.worldbank.org).

${ }^{9}$ http://www.sefin.gob.hn/erp.html

${ }^{10}$ http://www.sierp.hn/docs/Ref_LeyFRP_DEC76_2004.pdf; http://www.sierp.hn/docs/prop_ref_reglam_LeyFERP.pdf; and http://www.sierp.hn/docs/Prop_ref_reglam_CCERP.pdf

${ }_{12}^{11}$ HIPC completion point document Box 3.

${ }^{12}$ According to the 2004-2007 PRGF arrangement, poverty reduction spending is expected to reach 9.4 percent of GDP by 2006, an increase of about 2 percentage points of GDP with respected to the 2002 level.
} 


\section{G. Monitoring and Evaluation}

16. The Integrated Poverty Reduction Tracking System (SIERP) could be further enhanced by incorporating administrative data at the sectoral and municipal levels, and by reestablishing the interface with SIAFI to provide information on execution of antipoverty spending online. SIERP already provides broad access to and systematizes progress made to date in the implementation of the strategy, and it is a useful targeting tool for decision makers to allocate resources geographically by providing disaggregated information on progress made in attaining PRSP goals. SIERP website is: http://www.sierp.hn. Enhancing SIERP could bring about a very useful tool contributing to the formulation, execution and monitoring of PRSP programs, projects and indicators at the national, departmental and municipal levels. The system could also contribute to fiscal transparency by incorporating execution of disaggregated poverty reduction spending by programmatic area.

17. PSIAs were carried out to assess the economic and social impact of the tax reform packages and the impact of the rise in oil prices. The APR incorporates these PSIA results. SEFIN has incorporated PSIA findings into its action plans for strengthening revenue administration to ensure achievement of equity gains from the tax reform. The PSIA on tax reform determined the impact to be slightly progressive, both on vertical and horizontal equity grounds. ${ }^{13}$ The largest redistributive impact of the tax reform packages would come once they are fully implemented and complemented by progressive public spending. Thus, improvements in tax administration to reduce tax evasion and increase revenue collection will be key to the distributive gains of the reform. The work was coordinated by UNAT, under close collaboration with SEFIN, and with Bank technical and financial support.

18. Two other PSIAs have been initiated, on the distributional impact of public spending to be financed by the Bank, and on the wage policy to be financed by DFID. Programmed PSIAs include assessing potential social and economic impact of the implementation of DR-CAFTA and on the distributional impacts of public subsidies. Staffs attach particular importance to the redistributive impact and potential equity gains from public spending as well as the identification of potential winners and losers of the trade agreement. Compensatory actions should be prepared to address adverse effects on vulnerable groups. Staffs encourage the authorities to translate the poverty and inequality incidence analysis into specific anti-poverty policy actions and account on progress made in the next PRSP progress report.

${ }^{13}$ Vertical equity implies that those with greater ability to pay taxes should contribute a larger proportion of their income or wealth in taxes. Horizontal equity implies that those with equal ability to pay taxes should pay the same proportion in taxes. 


\section{CONCLUSIONS AND ISSUES FOR DISCUSSION}

\section{A. Risks to the Strategy}

\section{Despite the progress made in the implementation of the PRSP, including on some challenges identified in the previous joint staff assessment, the overall strategy faces significant risks, including:}

- $\quad$ Continued fiscal adjustment. In the near term, the progress achieved has been made possible by the strong domestic consensus in favor of reaching HIPC completion. This consensus, specifically on maintaining the tax ratio and prudent expenditures, could weaken after the completion point and in the run-up to the presidential election. Looking forward, although the controls over the public wage bill under the PRGF arrangement (2004-06) have been effective, the implementation of a permanent resolution to integrate teachers' benefits to their overall salaries before the 2007 budget is a critical element of a sustainable medium-term budget. In addition, although the implementation of CAFTA and the further opening of the telecommunications market to the private sector will boost growth prospects, there will also be a need for measures to offset lower tax and tariff revenue.

- Institutional weaknesses. While there have been significant advances in strengthening public financial management, risks to program implementation continue to be posed by weaknesses in the judiciary and the supreme audit agency (which is just now concluding its restructuring process). IDA's CAS contemplates technical and financial assistance for institutional building in all lending scenarios, and IDA is currently supporting enhancements to public sector management and judicial reform.

- $\quad$ Ensuring financial integrity and stability. While the passage of laws and regulations aimed at strengthening the financial system has reduced the risk of a financial crisis, the banking system is still weak and, thus, continues to pose significant risks to the PRSP. The Government of Honduras, supported by the IDA and the Fund, is addressing these risks by implementing a financial system reform that addresses the vulnerabilities identified in the 2003 FSAP with technical assistance and concessional funds from a Financial Sector Adjustment Technical Assistance Credit (FSTAC) and a Financial Sector Adjustment Credit (FSAC), respectively; utmost priority needs to be given to fully executing this reform.

- $\quad$ Enhancing the economy's resilience to shocks. External shocks and natural disasters could have a major negative impact on growth and consequently hamper poverty reduction. The authorities should ensure the economy's ability to absorb shocks and structural change, including by gradually moving toward a more flexible exchange rate system in the medium term. However, key preconditions for this include further strengthening of the financial sector and improving the monetary operations of the central bank. 
20. The APR would benefit from a more in-depth analysis of the risks to the strategy. The IDA and Fund staffs recommend that the authorities incorporate the analysis of these risks, including by outlining contingency measures, into the next PRSP progress report. The staffs also recommend that the immediate implementation of measures aimed at raising the likelihood of attaining PRSP/MDG goals be made a greater priority.

\section{B. Priority Areas for Strengthening the PRS and its Implementation}

\section{The APR presents a coherent medium-term macroeconomic framework and} credible efforts toward implementing the poverty reduction strategy. The staffs caution that although the economic outlook appears favorable, there are important risks and vulnerabilities, stemming from the wage policy framework, institutional weaknesses, consolidating the fiscal adjustment, ensuring financial stability, and enhancing the economy's resilience to shocks and safeguarding the program. These risks underscore the need for continued prudent macroeconomic policies, complemented by structural reforms to raise the competitiveness of the economy. Sustained macroeconomic stability and broadbased economic growth continue to be key elements for achieving policy objectives and strategy targets.

\section{Although the authorities have made significant progress in implementing the}

PRSP, further efforts are needed. Progress has been achieved, including on several areas cited in the assessment of the first APR as requiring further efforts, namely in:

- $\quad$ improving macroeconomic stability and reducing the fiscal deficit, while simultaneously achieving poverty-reducing spending targets,

- $\quad$ strengthening transparency in fiscal and public financial management systems (including SIAFI and continued improvements in the government's fiscal, financial and fiduciary management);

- $\quad$ consolidating the system of monitoring indicators (by developing SIERP);

- $\quad$ pursuing government-led efforts to realign donor assistance to the PRSP; and,

- $\quad$ understanding better the distributional impacts of reforms and external shocks, in particular by completing two PSIAs, on the tax reform and the rise in oil prices.

Nonetheless, areas where further work is needed include:

- continued fiscal consolidation, including through ensuring a sustainable wage policy, maintaining the tax ratio, and pursuing further public sector restructuring;

- $\quad$ financial stability by avoiding any slippages in the implementation of the authorities' financial system reform program;

- $\quad$ expanding the prioritization of programs at the sectoral level through costeffectiveness criteria; 
- $\quad$ identifying contingency measures to address the risks to the strategy, to ensure attaining PRSP/MDG goals; and

- $\quad$ scaling up social auditing mechanisms such as citizen report cards, to ensure that programs and projects translate into tangible and sustainable benefits to the population.

23. The staffs of the Bank and the Fund believe that the country's implementation of the strategy conveys its continuing commitment to poverty reduction. In fact, the PRSP law approved in 2004 with the support of all major political parties, places PRSP implementation above the electoral cycle by establishing that the fundamental objective of public policies is to reach the PRSP goals. ${ }^{14}$

24. Executive Directors may wish to focus on the following issues and questions:

- Do the Executive Directors concur with the areas identified by staffs as key implementation risks?

- Do the Executive Directors concur with the areas identified by staffs as priorities for strengthening the PRS and its implementation?

${ }^{14}$ The authorities have made explicit their commitment to implement the PRSP in the Law for Achieving Poverty Reduction (Decree 77-2004)

http://www.sierp.hn/docs/Ley_GestionRP_DEC77-2004.pdf. 